- Before any active orthodontic treatment is considered it is essential that the oral hygiene is of a high standard and that all carious leions have been dealt with

- Arch wires, headgears and brackets themselves may cause significant damage either during an active phase of treatment or during debonding. Much care needs to be taken when instructing patients about their role in orthodontic treatment

- The aim of this section is to outline potential risks in orthodontic treatment and to give examples. There are also a number of illustrations to help highlight these points

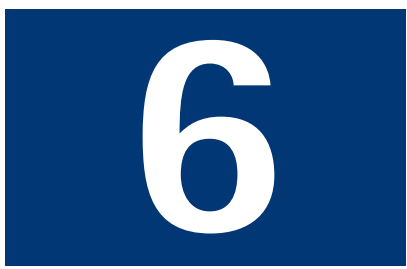

\title{
Orthodontics. Part 6: Risks in orthodontic treatment
}

\author{
H. Travess ${ }^{1}$, D. Roberts-Harry ${ }^{2}$ and J. Sandy ${ }^{3}$
}

\begin{abstract}
Orthodontics has the potential to cause significant damage to hard and soft tissues. The most important aspect of orthodontic care is to have an extremely high standard of oral hygiene before and during orthodontic treatment. It is also essential that any carious lesions are dealt with before any active treatment starts. Root resorption is a common complication during orthodontic treatment but there is some evidence that once appliances are removed this resorption stops. Some of the risk pointers for root resorption are summarised. Soft tissue damage includes that caused by archwires but also the more harrowing potential for headgears to cause damage to eyes. It is essential that adequate safety measures are included with this type of treatment.
\end{abstract}

ORTHODONTICS

1. Who needs orthodontics?

2. Patient assessment and examination I

3. Patient assessment and examination II

4. Treatment planning

5. Appliance choices

6. Risks in orthodontic treatment

7. Fact and fantasy in orthodontics

8. Extractions in orthodontics

9. Anchorage control and distal movement

10. Impacted teeth

11. Orthodontic tooth movement

12. Combined orthodontic treatment

${ }^{1}$ Senior Specialist Registrar, ${ }^{2}$ Consultant Orthodontist, Orthodontic Department Leeds Dental Institute, Clarendon Way, Leeds LS2 9LU; ${ }^{3}$ Professor of Orthodontics, Division of Child Dental Health, University of Bristol Dental School, Lower Maudlin Street, Bristol BS1 2LY

\section{Refereed Paper}

doi:10.1038/sj.bdj.4810891

(๑) British Dental Journal 2004; 196:

71-77
If orthodontic treatment is to be of benefit to a patient, the advantages it offers should outweigh any possible damage it may cause. ${ }^{1}$ It is important to assess the risks of treatment as well as the potential gain and balance these aspects of treatment before deciding to treat a malocclusion. The psychological trauma of having orthodontic treatment, or indeed not having treatment should not be overlooked and is an important consideration in treatment planning. Patient selection plays a vital role in minimising risks of treatment and the clinician should be vigilant in assessing every aspect of the patient and their malocclusion. However, clinically there are a number of areas of concern for risk management. These are discussed in detail under the broad categories of intra-oral, extra-oral and systemic risks.

\section{INTRA-ORAL RISKS}

\section{Enamel demineralisation/caries}

Enamel demineralisation, usually on smooth surfaces, is unfortunately a common complication in orthodontics; figures range from $2-96 \%$ of orthodontic patients (Fig.1). ${ }^{2}$ This large variation probably arises as a result of the variety of methods used to assess and score the presence of decalcification. There is also inconsistency on whether idiopathic lucencies are included or excluded in the study design. ${ }^{3}$ The teeth most commonly affected are maxillary lateral incisors, maxillary canines and mandibular premolars. ${ }^{4}$ However, any tooth in the mouth can be affected, and often a number of anterior teeth show decal-

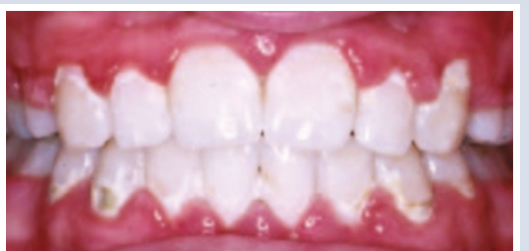

Fig. 1 Decalcification on labial surfaces of numerous teeth

cification. Whilst the demineralised surface remains intact, there is a possibility of remineralisation and reversal of the lesion. In severe cases, frank cavitation is seen which requires restorative intervention (Figs. 2 and 3).

Gorelick et al..$^{5}$ in a study on white spot formation in children treated with fixed appliances, found that half of their patients had at least one white spot after treatment, most commonly on maxillary lateral incisors. The length of treatment did not affect the incidence or number of white spot formations, although 0'Reilly and Featherstone $^{6}$ and Oggard et al. ${ }^{7}$ found that demineralisation can occur rapidly, within the first month of fixed appliance treatment. This has obvious aesthetic implications and highlights the need for caries rate assessment at the beginning of treatment. Interestingly, Gorelick et $a l .{ }^{5}$ found no incidence of white spot formation associated with lingual bonded retainers, which would suggest salivary buffering capacity, and flow rate have a role in protection against acid attack. 


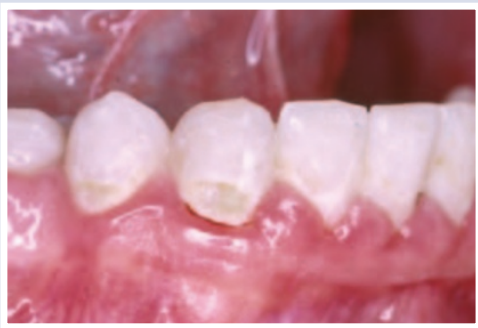

Fig. 2 Cavitation at the gingival margin of the lower right canine and first premolar requiring restoration

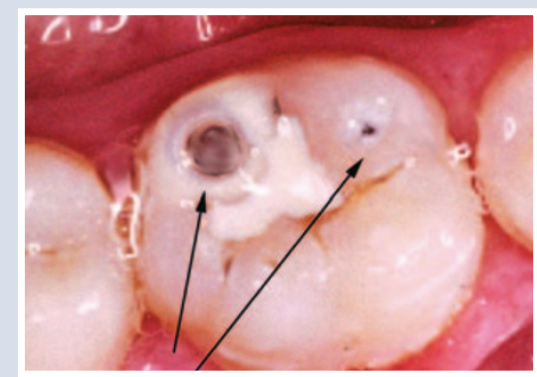

Fig. 3 Obvious caries in the disto-occlusal aspect of a lower molar

The dominant hand may also influence the area of decalcification as brushing is more difficult on the side of the dominant hand. Whilst good oral hygiene is vital, dietary control of sugar intake is also needed in order to minimise the risk of decalcification. Fluoride mouthwashes used throughout treatment can prevent white spot formation ${ }^{8}$ surprisingly, compliance with this is low (13\%). Other fluoride release mechanisms include fluoride releasing bonding agents, elastic ligatures containing fluoride, and depot devices on upper molar bands. ${ }^{9}$

Preventive measures to minimise damage include patient selection, vigorous oral hygiene measures and dietary education. Reinforcement of oral hygiene and dietary education should be performed at each visit. Positive reinforcement even where oral hygiene is satisfactory will encourage the patient further. Inspection of the labial surfaces of the teeth at each adjustment appointment will identify cases that require more intervention and advice. It is important when examining the teeth that they are plaque-free otherwise early demineralisation may be missed. This can be done by instructing the patient to clean their teeth in the surgery with or without the wires in place, or by professional prophylaxis. The use of auxillaries such as dental health educators and hygienists is highly desirable. Removal of the appliance in cases with extreme demineralisation or poor hygiene is the last resort, but should not be discounted by the clinician.

Where demineralisation is present post treatment, fluoride application either via toothpaste, or by adjunct fluoride mouthwash $(0.05 \%$ sodium fluoride daily rinse or $0.2 \%$ sodium fluoride weekly rinse), can be helpful in remineralising the lesion and reducing the unsightliness of the decalcification. ${ }^{10}$ Acid/pumice micro abrasion has also been advocated to improve the aesthetics of stabilised lesions. ${ }^{11,12}$ This procedure should be delayed at least 3 months following debond to allow for spontaneous improvement of the lesions and remineralisation with fluoride applications. ${ }^{13}$ Persistent lucencies should be abraded with 18\% hydrochloric acid in fine pumice under rubber dam in bursts of 30 seconds for a maximum of 10 times. After the last application the tooth is washed well and a fluoride varnish applied. ${ }^{11}$

\section{Enamel trauma}

When placing appliances careless use of a band seater can result in enamel fracture. Care is required when large restorations are present since these can result in fracture of unsupported cusps. ${ }^{14}$ Debonding can also result in enamel fracture, both with metal and ceramic brackets (Fig. 4). ${ }^{15,16}$ Care must always be taken to remove brackets and residual bonding agents appropriately to minimise the risk of enamel fracture. The use of debonding burs has the potential to remove enamel, especially in air turbine fast handpieces. Care and attention is needed when adhesives are removed.

\section{Enamel wear}

Wear of enamel against both metal and ceramic brackets (abrasion) may occur. It is common on upper canine tips during retraction as the cusp tip hits the lower canine brackets (Fig. 5). It may also be seen on the incisal edges of upper anterior teeth where ceramic brackets are placed on lower incisors. ${ }^{17}$ Ceramic brackets are very abrasive and therefore contraindicated for the lower anterior teeth where there is any possibility of the brackets occluding with the upper teeth, bearing in mind that the overbite may

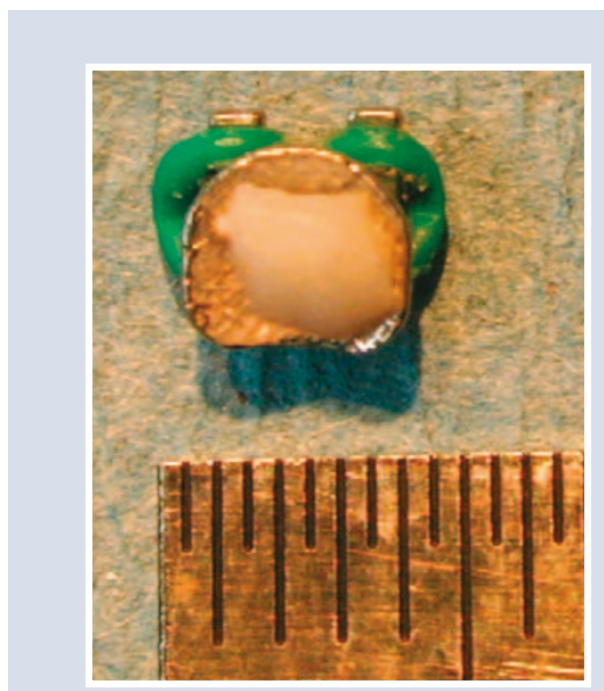

Fig. 4 Enamel fracture at debond 




Fig. 5 Upper canine tip showing abrasion from the lower canine metal bracket

increase in the early stages of treatment. Any enamel erosion must be recorded prior to treatment commencing and appropriate dietary advice given to minimise further tooth substance loss. Carbonated drinks and pure juices are the commonest causes of erosion and should be avoided in patients with fixed appliances.

\section{Pulpal reactions}

Some degree of pulpitis is expected with orthodontic tooth movement which is usually reversible or transient. Rarely it leads to loss of vitality, but there may be an increase in pulpitis in previously traumatised teeth with fixed appliances. Light forces are advocated with traumatised teeth as well as baseline monitoring of vitality which should be repeated three monthly. ${ }^{18}$ Transient pulpitis may also be seen with electrothermal debonding of ceramic brackets ${ }^{19}$ and composite removal at debond. ${ }^{20}$

\section{Root resorption}

Some degree of external root resorption is inevitably associated with fixed appliance treatment, although the extent is unpredictable. ${ }^{21}$ Resorption may occur on the apical and lateral surface of the roots, but radiographs only show apical resorption to a certain degree. Many cases will not show any clinically significant resorption but, microscopic changes are likely to have occurred on surfaces which are not visualised with routine radiographs. Resorption however rarely compromises the longevity of the teeth. ${ }^{22}$ Vertical loss of bone through periodontal disease creates a far greater loss of attachment and support than its equivalent loss around the apex of a tooth.

The mechanism of tooth resorption is unclear. Theories include excessive force and hyalinisation of the periodontal ligament resulting in excessive cementoclast and osteoclast activity. What is clear are the risk factors which are associated with cases with severe resorption. These can be summarised as:

- Blunt and pipette shaped roots show a greater amount of resorption than other root forms.
- Short roots are more at risk of resorption than average length roots.

- Teeth previously traumatised, have an increased risk of further resorption.

- Non vital teeth and root treated teeth have an increased risk of resorption.

- Heavy forces are associated with resorption, as well as the use of rectangular wires, Class II traction, the distance a tooth is moved and the type of tooth movement undertaken.

- Combined orthodontic and orthognathic procedures.

Treatment of ectopic canines may induce resorption of the adjacent teeth because of the length of treatment time and the distance the canine is moved. Tooth intrusion is also associated with increased risk as well as movement of root apices against cortical bone. Above the age of 11 years the risk of resorption with treatment seems to increase. Adults have shorter roots at the outset and the potential for resorption is increased.

Opinion is divided on whether treatment length is associated with increased resorption. Some find no correlation with treatment time, whereas others find that there is increased resorption with increased treatment time. In a few patients systemic causes may contribute, for example hyperthyroidism, but for the most part no underlying cause is isolated other than individual susceptibility. Familial risk is also known.

A wide range in the degree of resorption is seen, highlighting the role of individual susceptibility over and above the risk factors identified. Research is still required in this area to identify the mechanisms of resportion, trigger factors and reparative mechanisms if treatment modalities are to be modified in the future to minimise root damage. Currently, no case is immune from the risk of root resorption, to some degree, and patients should be warned at the outset of treatment that such a risk exists. Recognition of specific risk factors, accurate radiographs and interpretation of radiographs at the outset of treatment are important if root resorption is to be minimised. Once resorption is recognised clinically during treatment, light forces must be used, root length monitored six monthly with radiographs and treatment aims reconsidered to maximise the longevity of the dentition. The use of thyroxine to minimise root resorption has been advocated by some authors, but this is not routinely used. ${ }^{23,24}$

\section{Periodontal tissues}

Fixed appliances make oral hygiene difficult even for the most motivated patients, and almost all patients experience some gingival inflammation (Fig. 6). Resolution of inflammation usually occurs a few weeks after debond, bands cause more gingival inflammation than bonds, which is not surprising since the margins of bands are often seated subgingivally.
- Root resorption is inevitable with fixed appliance treatment

- On average 1-2 $\mathrm{mm}$ of apical root is lost during a course of orthodontic treatment

- Previously traumatised teeth have an increased risk of root resorption 


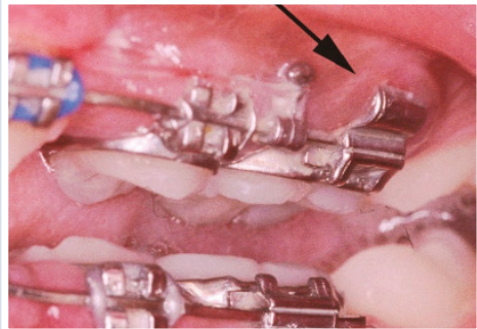

Fig. 6 Severe gingival inflammation during fixed appliance treatment. Note the inflammation covers the headgear tube and hook on the upper molar band

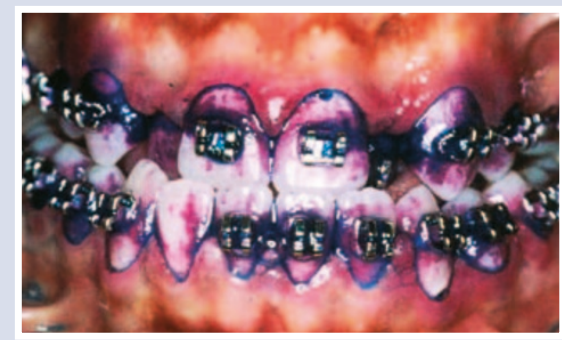

Fig. 7 Disclosing solution highlighting the areas of poor oral hygiene in a patient

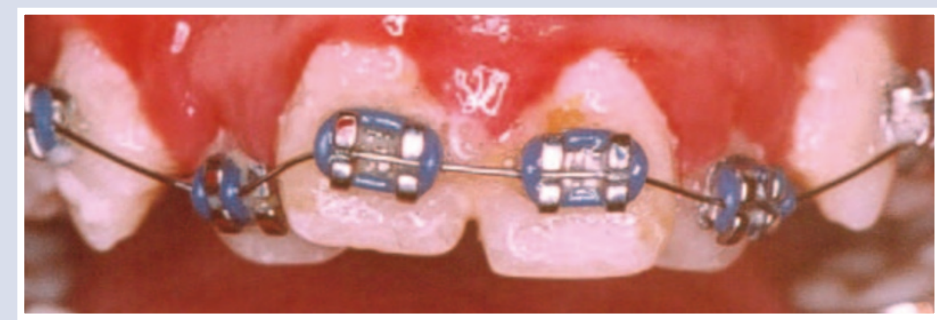

Fig. 8 Chronic lack of oral hygiene showing accumulation of plaque gingivally and around the brackets
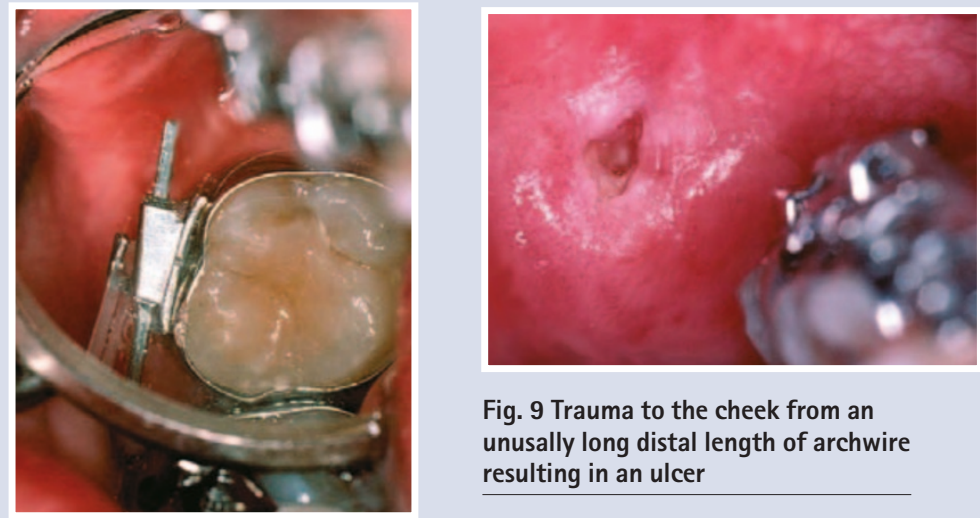

Fig. 9 Trauma to the cheek from an unusally long distal length of archwire resulting in an ulcer
For the most part, the literature suggests that orthodontic treatment does not affect the periodontal status of patients over the long term. Patients with pre-existing periodontal disease require special attention, but bone loss during treatment does not seem to be related to previous bone loss. The need for excellent oral hygiene during treatment must be emphasised in patients with existing periodontal disease. The use of bonds rather than bands on molars and premolars may be more appropriate to eliminate unwanted stagnation areas. Plaque retention is increased with fixed appliances and plaque composition may also be altered. There is an increase in anaerobic organisms and a reduction in facultative anaerobes around bands, which are therefore periopathogenic. $^{25}$

Oral hygiene instruction is essential in all cases of orthodontic treatment, and the use of adjuncts such as electric toothbrushes, interproximal brushes, chlorhexidine mouthwashes, fluoride mouthwashes and regular professional cleaning must be emphasised. However, patient motivation and dexterity are paramount in the success of hygiene, and there will always be cases where oral hygiene is unsatisfactory from the outset. This should be carefully considered when advising a patient to have treatment. Experience shows those patients who are unable to maintain a healthy oral environment in the absence of fixed orthodontics will fail spectacularly with braces in place. Benefit must therefore significantly outweigh the risk of carrying out treatment in such patients (Figs. 7 and 8).

\section{Allergy}

Allergy to orthodontic components intraorally is exceedingly rare, however, there have been studies on the nickel release and corrosion of metals with fixed appliances. Gjerdet et al. ${ }^{26}$ found a significant release of nickel and iron into the saliva of patients just after placement of fixed appliances. However, no significant difference was found in nickel or iron concentrations between controls and subjects where the appliances had been in place for a number of weeks. The clinical significance of nickel release is as yet unclear, but should be considered in nickel sensitive patients. There are a few cases with severe latex allergies who may be affected by elastomerics or operators gloves.

\section{Trauma}

Laceration to the gingivae, and mucosa seen as areas of ulceration or hyperplasia, often occur during treatment or between treatment sessions from the archwire (Fig. 9) and bonds, especially where long unsupported stretches of wire rest against the lips. The use of dental wax over the bracket may help to reduce trauma and discomfort, (Fig. 10) as may rubber bumper sleeving on the unsupported archwire (Fig. 11). 


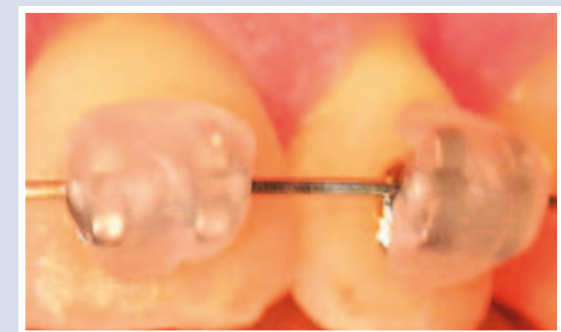

Fig. 10 Dental wax placed over a bracket can ease the pain of ulceration in the lip and mucosa

\section{EXTRA-ORAL RISKS}

\section{Allergy}

Allergy to nickel is more common in extra-oral settings, most usually the headgear face bow or head strap. Over $1 \%$ of patients have some form of contact dermatitis to zips and buttons/studs on clothing. Of these patients, 3\% claim to have experienced a similar rash with orthodontic appliances (Fig. 12). The use of sticking plaster over the area in contact with the skin is sufficient to relieve symptoms. Allergy to late ${ }^{27}$ and bonding materials has been reported although these are rare.

\section{Trauma}

Following a well publicised case of eye trauma in a patient wearing headgear ${ }^{28}$ a number of safety headgear products have been designed and explicit guidelines are now available. These measures include safety bows (Figs 13 and 14), rigid neck straps (Fig. 15) and snap release products (Fig. 16) to prevent the bow from disengaging from the molar tubes or acting as a projectile. A survey among British orthodontists found a $4 \%$ incidence of facial injury with headgear. Of these injuries, 40\% were extra-oral and 50\% of these were in the mid face. Two patients were blind as a result of headgear trauma. Eye injury is uncommon, but a serious risk and all available methods of reducing the risk of penetrating eye injury must be used. Every headgear and Kloehn

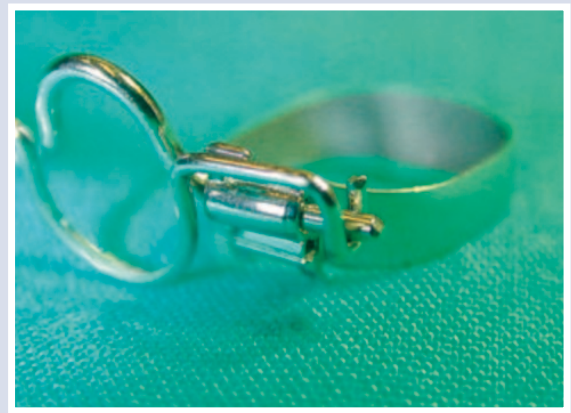

Fig. 13 Safety Kloehn bow showing recurved loops for smooth distal ends to prevent injury if the bow becomes disengaged bow must incorporate a safety feature. Failure to observe safety guidelines on the use of headgear is medico-legally indefensible.

\section{Burns}

Burns, either thermal or chemical are possible both intra- and extra-orally with inadvertent use of chemicals or instruments. Acid etch, electrothermal debonding instruments and sterilised instruments which have not cooled down all have the potential to burn and care should be taken in their use.

\section{Tempromandibular dysfunction (TMD)}

Much attention in the literature has been focused on the relationship between TMD and orthodontic treatment. Whilst TMD is common in the orthodontic aged population whether orthodontic treatment is carried out or not, there is no evidence to support the theory that orthodontic treatment causes TMD or cures it. ${ }^{29}$ Pre-existence of TMD should be recorded, and the patient advised that treatment will not predictably improve their condition. Some patients may suffer with increased symptoms during treatment which must also be discussed at the beginning of treatment. Where patients experience symptoms during treatment, treatment should be directed at eliminating occlusal disharmony and joint noises whilst reassuring the patient. Standard
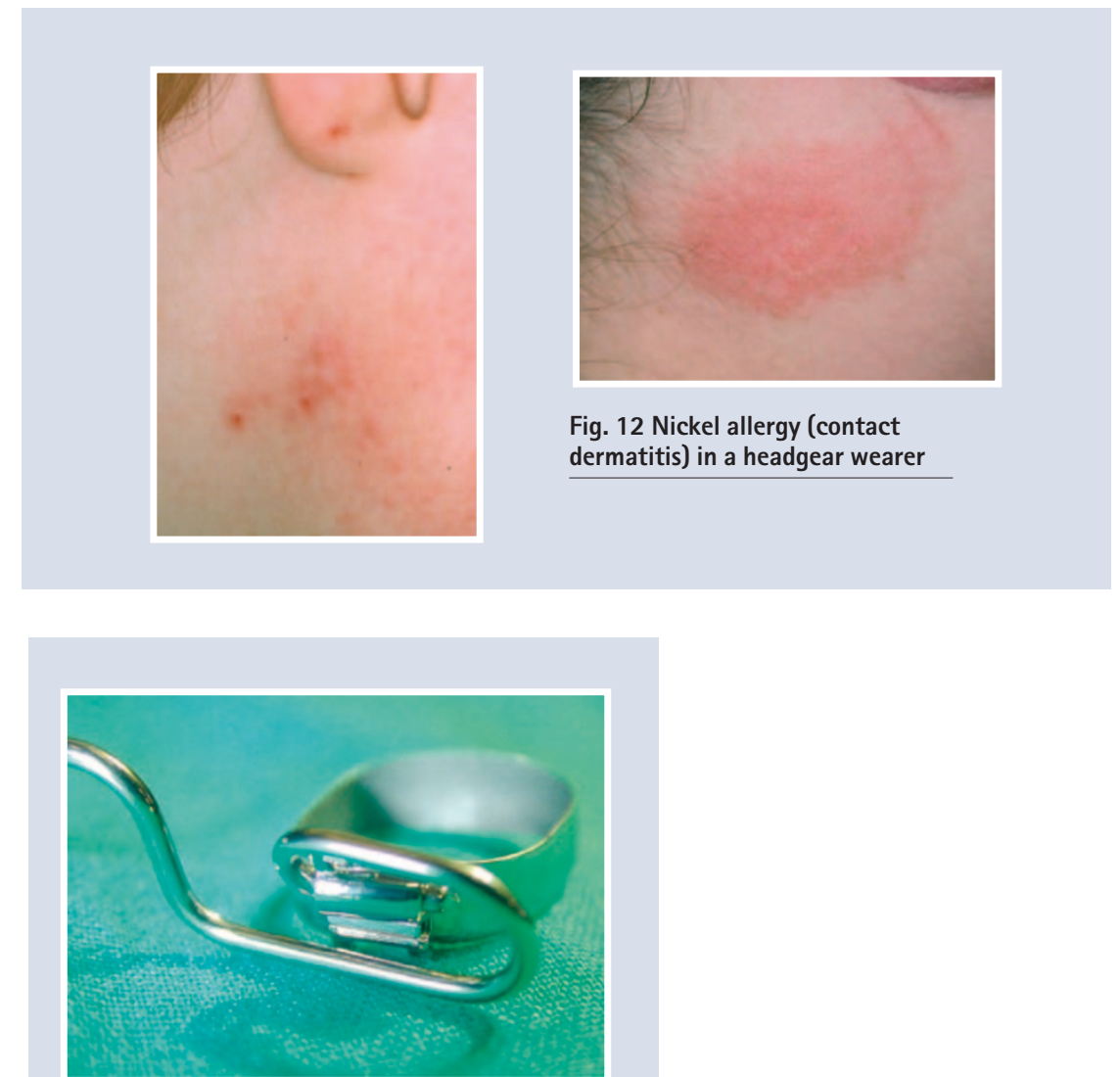

Fig. 14 Safety Kloehn bow with Nitom locking mechanism to prevent disengagement from the molar tube

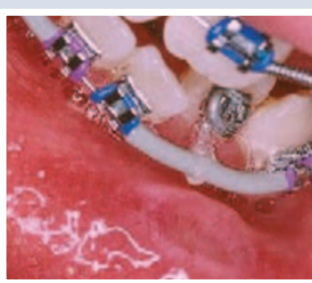

Fig. 11 Ulcer in a patient's lower lip from a long stretch of unsupported wire. Bumper sleeve has been placed along the wire to prevent further trauma 


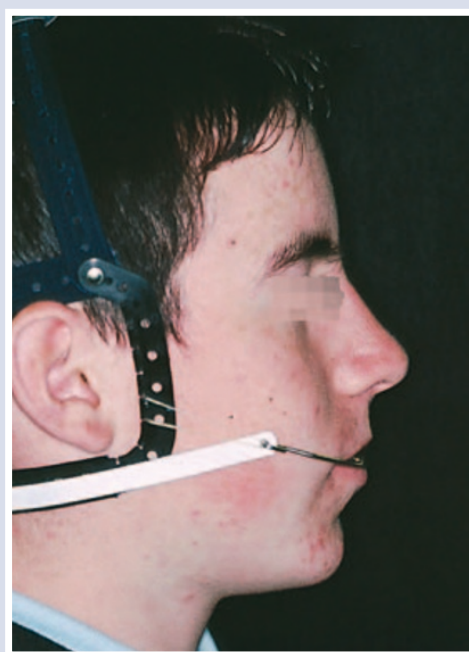

Fig. 15 Interlandi headgear with a rigid Masel safety strap to hold the Kloehn bow and prevent disengagement for the buccal tubes

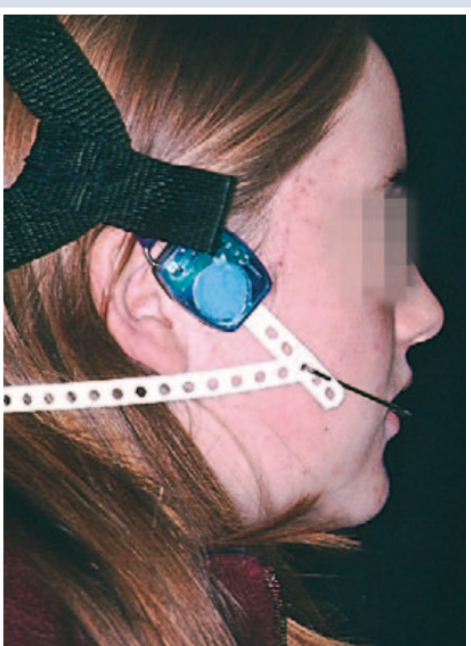

Fig. 16 Quick release headgear attachment. The breakaway design allows the bow to come out of the headgear tube, but is no longer under tension and therefore unable to act as a projectile treatment regimes may also be indicated eg soft diet, jaw exercises. We have not reviewed this area in detail in this section as it is dealt with under facts and fantasy in the next, but an excellent overview of the relation between orthodontics and occlusal relation has recently been published. ${ }^{30}$

\section{Profile damage}

Extraction of premolars has been condemned by some with very little evidence, as altering the facial profile of the patient. ${ }^{31}$ A large number of studies have shown that there is no significant difference in profiles treated by extraction or non extraction means. Boley et al. $^{32}$ found that neither orthodontists nor general dentists could distinguish between extraction and non extraction treatment by looking at profile alone. A recent review examined the effects of orthodontics on facial profie and concluded that it does not, although it highlights areas where planning is crucial. ${ }^{33}$ It should be remembered that soft tissue changes occur naturally with age, regardless of orthodontic intervention. Proper diagnosis should take into account skeletal form, tooth position and soft tissue form to negate the possibility of any detrimental effect on profile by treatment mechanics. $^{34}$

\section{SYSTEMIC RISKS}

\section{Cross infection}

Spread of infection between patients, between operator and patient and by a third party should be prevented by cross infection procedures throughout the surgery. Use of gloves, masks, sterilised instruments and 'clean' working areas are paramount. A medical history must be taken for every patient to determine risk factors, although cross infection control should be of a standard to prevent cross contamination regardless of medical status.

\section{Infective endocarditis}

Patients at risk of endocarditis should be treated in consultation with their cardiologist and within the appropriate guidelines. ${ }^{35,36}$ The patient must exhibit immaculate oral hygiene, antibiotic cover will be required for invasive procedures such as extractions, separation, band placement and band removal. It is recommended that bonded attachments are used on all teeth to negate the need for antibiotic cover for both separator and band placement, as well as removal. This also reduces the risk of unwanted plaque stagnation areas. Chlorhexidine mouthwash has been advocated prior to any treatment and in some cases daily to minimise bacterial loading. ${ }^{36}$

\section{CONCLUSIONS}

Clearly there are a number of sources of potential iatrogenic damage to the patient during orthodontic treatment. However, severe damage is rare. Severe malocclusions have more to benefit from treatment than less severe malocclusions, and motivation between such groups may vary. Individuals should be assessed for risk factors for all aspects of care. Lack of treatment can result in damage, physical or psychosocial. Discontinuation of treatment without full correction of the malocclusion, although a last resort, can leave the patient worse off than before treatment. Good clinical practice, careful patient selection and information on a patient's responsibility are essential to minimise tissue damage.

The authors are grateful to Francis Scriven, Thomas Hartridge and Ingrid Hosein for some of the figures and Jane Western who cheerfully typed this manuscript. 
1. Shaw W C, O'Brien KD, Richmond S, Brook P. Quality control in orthodontics: risk/benefit considerations. Br Dent J1991; 170: 33-37.

2. Chang H S, Walsh L J, Freer TJ. Enamel demineralisation during orthodontic treatment. Aetiology and prevention. Aus Dent J 1997; 42: 322-327.

3. Mitchell L. Decalcification during orthodontic treatment with fixed appliances - An overview. Br J Orthod 1992 ; 19: 199205.

4. Geiger A M, Gorelick L, Gwinnett A J, Griswold P G. The effect of a fluoride program on white spot formation during orthodontic treatment. Am J Orthod Dento Orthop 1988; 93 29-37.

5. Gorelick L, Geiger A M, Gwinnett A J. Incidence of white spot formation after bonding and banding. Am J Orthod 1982: 81:93-98.

6. O'Reilly M, Featherstone J. Demineralisation and remineralisation around orthodontic appliances - an in vivo study. Am J Orthod Dento Orthop 1987; 92: 33-40.

7. Öggard B, Rølla G, Arends J. Orthodontic appliances and enamel demineralisation. Part 1. Lesion development. Am J Orthod Dento Orthop 1988; 94: 68-73.

8. Geiger A M, Gorelick L, Gwinnett A J. Griswold P G. Effect of a fluoride program on white spot formation during orthodontic treatment. Am J Orthod Dento Orthop 1988; 93 29-37.

9. Marini I, Pelliccioni G A, Vecchiet F, Alessandri Bonetti G, Checchi $\mathrm{L}$. A retentive system for intra-oral fluoride release during orthodontic treatment. Eur J Orthod 1999; 21 : 695-701.

10. Featherstone J D B, Rodgers B E, Smith M W. Physiochemical requirements for rapid remineralisation of early carious lesions. Caries Res 1981: 15: 221-235.

11. Welbury R R, Carter N E. The hydrochloric acid-pumice microabrasion technique in the treatment of post orthodontic decalcification. Br J Orthod 1993; 108: 181-185.

12. Elkhazindar M M, Welbury R R. Enamel Microabrasion. Dent Update 2000; 27: 194-196.

13. Artun J, Thylstrup A. Clinical and scanning electron microscopic study of surface changes of incipient caries lesions after debonding. Scand J Dent Res 1986; 94: 193-201.

14. McGuinness N. Prevention in orthodontics - a review. Dent Update 1992; 19: 168-175.

15. Meister RE. Comparison of enamel detachments after debonding between uniteck's dynalok bracket and a foil mesh bracket: a scanning electron microscope study. Am J Orthod 1985; 88: 266 (abstract).

16. Jones M. Enamel loss on bond removal. Br J Orthod 1980; 7:39.

17. Swartz M L. Ceramic brackets. J Clin Orthod 1988; 22: 82-88.

18. Atack N E. The orthodontic implications of traumatised upper anterior teeth. Dent Update 1999; 26: 432-437.
19. Takla P M, Shivapuja P K. Pulpal response in electrothermal debonding. Am J Orthod Dento Orthop 1995; 108: 623-629.

20. Zachrisson B U. Cause and prevention of injuries to teeth and supporting structures during orthodontic treatment. Am J Orthod 1976: 69: 285-300.

21. Brezniak N, Wasserstein A. Root resorption after orthodontic treatment Part I Literature review. Am J Orthod 1993; 103: 62-66.

22. Hendrix I, Carels C, Kuijpers-Jagtman A M, Van 'T Hof M A radiographic study of posterior apical root resorption in orthodontic patients. Am J Orthod Dento Orthop 1994; 105: 345-349.

23. Shirazi M, De Hpour A R, Jafari F. The effect of thyroid hormone on orthodontic tooth movement in rats. J Clin Paed Dent 1999; 23: 259-264.

24. Loberg E L, Engstrom C. Thyroid administration to reduce root resorption. Angle Orthod 1994; 64: 395-399.

25. Diamanti-Kipioti A, Gusberti FA, Lang N P. Clinical microbiological effects of fixed orthodontic appliances. J Clin Perio 1987; 14: 326-333

26. Gjerdet N, Erichsen ES, Remlo H E, Evjen G. Nickel and iron in saliva of patients with fixed orthodontic appliances. Acta Odont Scand 1991:49: 73-78.

27. Natrass C, Ireland A J, Lovell C R. Latex allergy in an orthodontic patient and implications for clinical management. Br J Oral Maxillofac Surg 1999; 37: 11-13.

28. Booth-Mason S, Birnie D. Penetrating eye injury from orthodontic headgear: a case report. Eur J Orthod 1988; 10 111-114.

29. Luther F. Orthodontics and the temperomandibular joint: where are we now? Part 1 Orthodontic treatment and temperomandibular disorders. Angle Orthod 1998; 68 295-304.

30. Davies S J, Gray R M J, Sandler P J, O'Brien K D. Orthodontics and occlusion. Br Dent J2001; 191: 539-549.

31. Rushing SE, Silberman S L, Meydrech E F, Tuncay O C. How dentists perceive the effect of orthodontic extraction on facial a ppearance. J Am Dent Assoc 1995; 126: 769-772.

32. Boley J C, Pontier J P, Smith S, Fulbright M. Facial changes in extraction and non extraction patients. Angle Orthod 1998; 68: 539-546.

33. DiBiase A T, Sandler P J. Does Orthodontics damage faces? Dent Update 2001; 28: 98-104

34. Ackerman $J$ L, Proffit W R. Soft tissue limitations in orthodontics: treatment planning guidelines. Angle Orthod 1997; 67: 327-336

35 Khurana M, Martin M V. Orthodontics and infective endocarditis. Br J Orthod 1999; 26: 295-298.

36. Hobson R S, Clark J D. Management of the orthodontic patient at risk from infective endocarditis. Br Dent J 1995; 178: 289-295. 